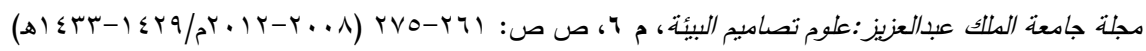
DOI: 10.4197 / Evn. 6.10

\title{
مؤسسات التصميم الهندسي المعماري في المملكة العربية السعودية: التخطيط الاستراتيجي وكفاءة ممارسة المهنة
}

\section{عدنان عباس علس}

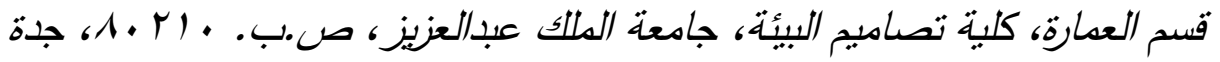

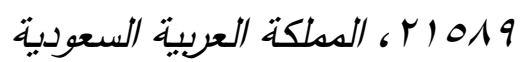

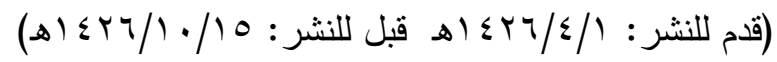

المستخلص. مـع انضـمام المملكـة العربيـة السـعودية لنظـام التجـارة

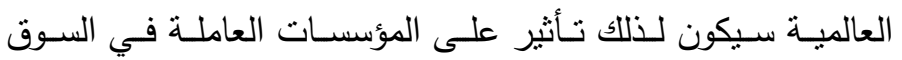

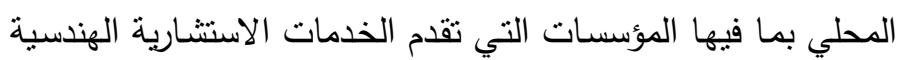

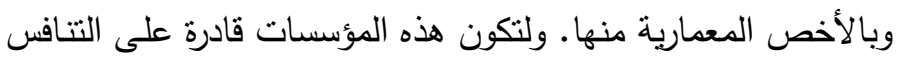

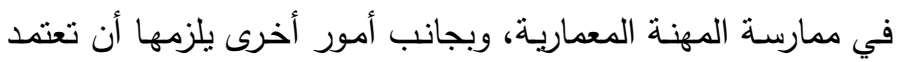

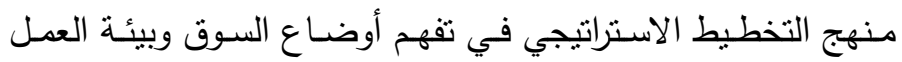

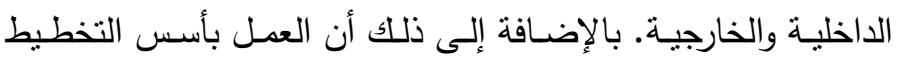
الاستراتيجي سيؤدي إلى رفع كفاءة أداء المؤسسات المعمارية ويؤهلها لخوض الصراع على البقاء وبصورة أفضل.

يناقش هذا البحث باختصـار أنمـوذج نظري يوضـح مراحل

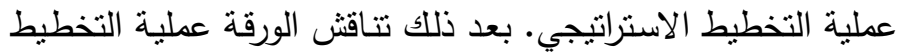
الاسـتراتيجي مـن منظـور مؤسســات تقـديم الخـدمات الاستشــارية

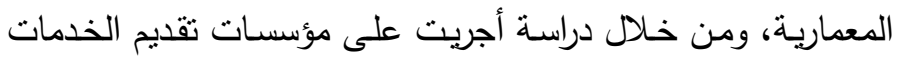

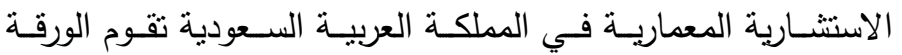


بإعطـاء نظــرة ســريعة لوضــع المؤسســات التــي تقــدم الخـدمات

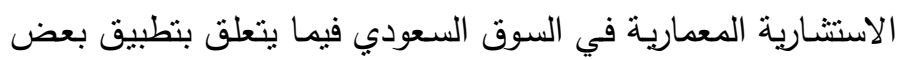

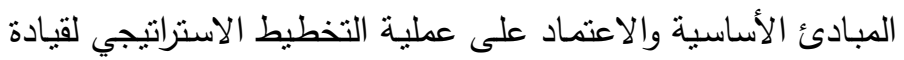
سفينة المؤسسة إلى بر الأمان. قامت الدراسة بتقيبيم مستوى قوة نقافية

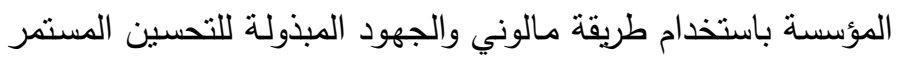

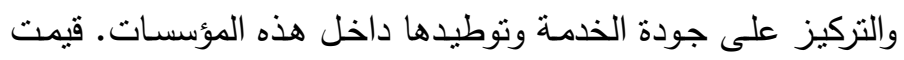

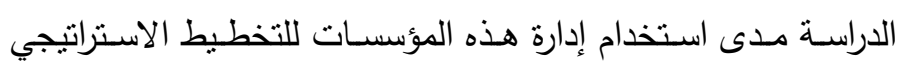

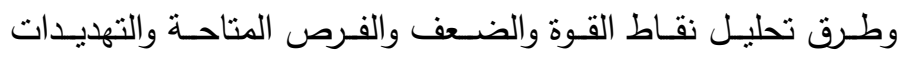

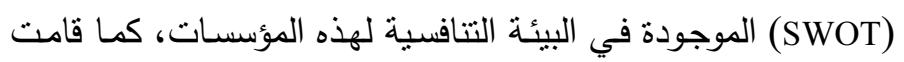

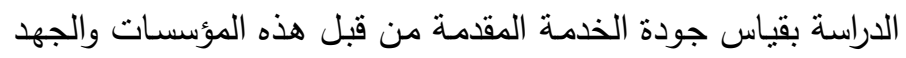

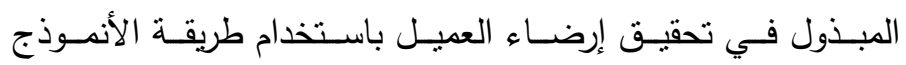

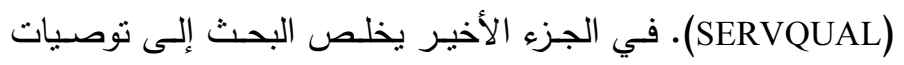

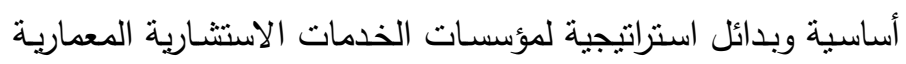

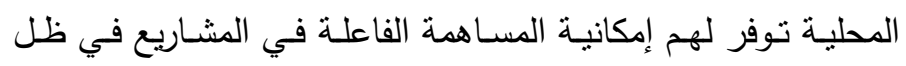
نظام التجارة العالمية.

\section{1. مقدمة}

يمكــن تقـــيم مهـــام الإدارة فــي المنشـــأة/المؤسســـة أو المنظمــة الربحيــة (planning) إلـى أربعـة مهـام رئيسـية تشـمل التخطـيط (firm/organization) والتظظـيم (organization)، والقبـادة والتوجيــه (leadership)، والرقابــة والسـيطرة

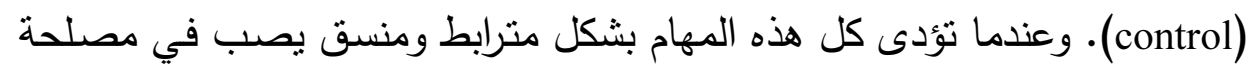

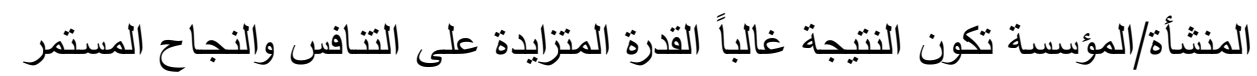
للمنظمـة. ولمهمـة التخطيط أهميـة عظمسى ودور كبيـر في النجـاح ورفـع الأداء خاصة فيما يتعلق بموضوع الجودة حيث تركز وتشدد عليه معظم النظريات التي total بـرزت مؤخراً في التسـعينيات مسن تطبيـق لمبـادئ إدارة الجودة الثـاملة (quality management وتطبيق سلاسـل الأيزو العالميـة (9000 2SO) ومبادئ 
إعادة هندسة العمليات الإدارية (re-engineering) والإنتاج الذي ينطلب التخطيط الزمني للموارد (just in time production) إلى عمارة المنظمات ( organizational

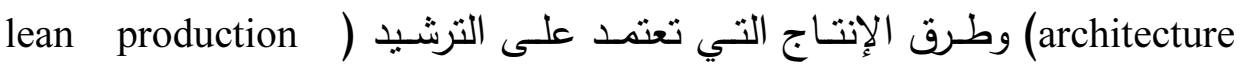

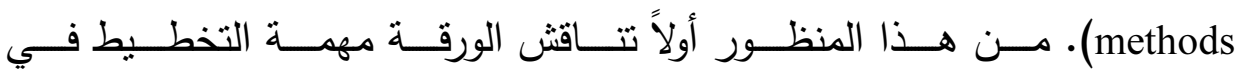

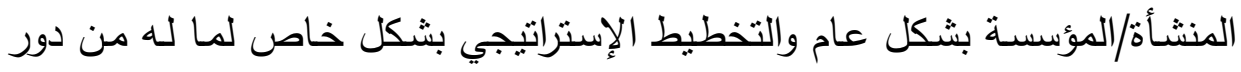

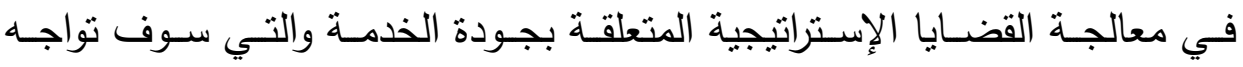
مؤسسات الخدمات الاستشـارية المعماريـة في ظل نظام التجارة العالمي كقضية

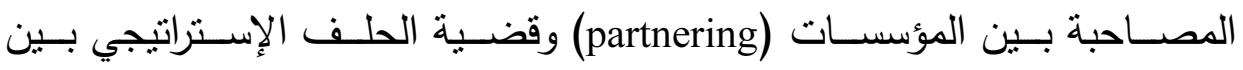
المؤسسات (strategic alliances) والقضايا التتفيذية المتعلقة بتحسين الأداء في

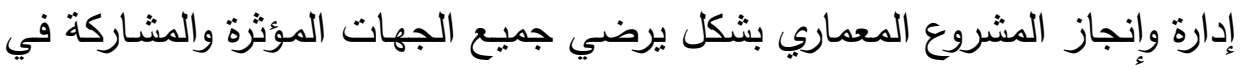

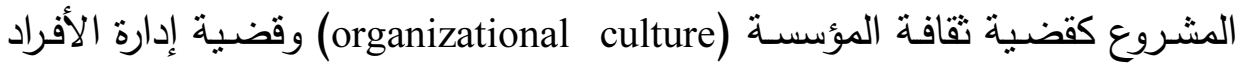

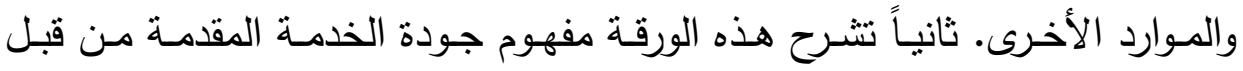

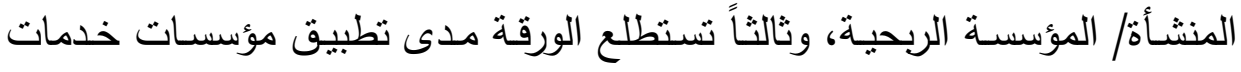

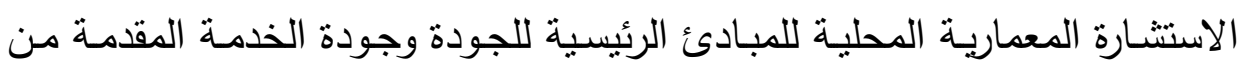

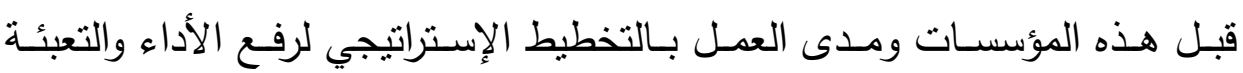
والاستعداد لخوض المعركة المنظظرة.

\section{ب التخطيط الاستراتيجي}

عملية التخطيط بشكل عام هي رسم الأهداف العليا للمؤسسة التي تتقق مع فئس

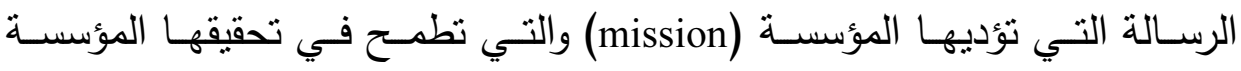

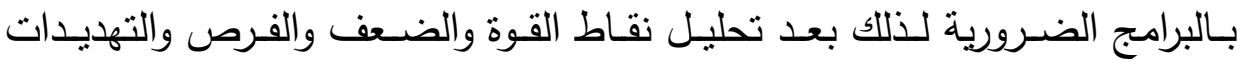

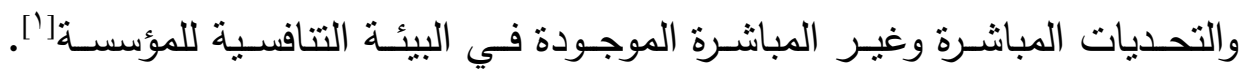
التخطيط الإستراتيجي يعتمد بشكل رئيسي على تحليل نقاط القوة والضعف والفرص

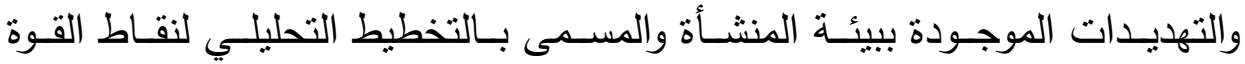


والضعف والفرص والتهديدات ( Strengths, Weaknesses, Opportunities, and (Threats Analysis or SWOT وهذا النوع من التخطيط يشكل الأسـاس الذي تقوم عليه عملية التخطيط السليم وبدونه يكون العمل ارتجالي، مما يؤدي إلى التذبذب لهن في الأداء وفي النهايـة عدم بلـوغ الأهداف الموضـوعة للمؤسسـة. تتضـح أهميـة التخطيط في ظل النظام التجاري الجديد خاصـة وأنه يوماً بعد يوم تشتـ المنافسة

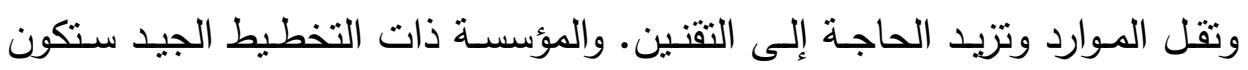

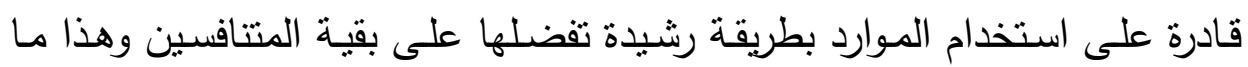
يرنو إليه هذا النظام الجديد فالمنتجين المكلفين سوف يذهبوا بدون رجعة[َّ. فمن

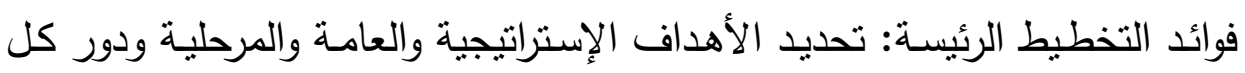
عنصـر في المؤسسـة، برمجـة المـوارد المتاحـة بـالكم والكيف، وتوظيف القدرات المتاحة للمؤسسة بشكل أفضل، ويساعد على التتبؤ بما قد بطرأ من مشاكل ووضع كيفية للتعامل مع المتغيرات في السوق التتافسي للمؤسسة. إن التخطيط الاسـتراتيجي هـو مـن مهام الإدارة العليـا ويقصـد بـه الخطط

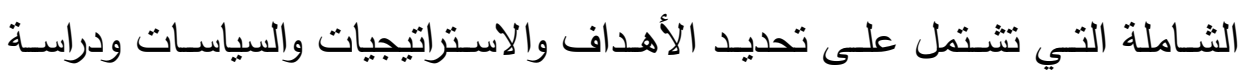
المتغيرات وتحليلها وتحديد البدائل وتقويمها واختيار الأفضل منها والمتابعة وهذا هو النوع من التخطيط الاستراتيجي التحليلي الذي يطلق عليه (SWOT). ويمر ولئر التخطيط الاستراتيجي بـأربع مراحل وهي مرحلة الإعداد ومرحلة الإقرار ومرحلة

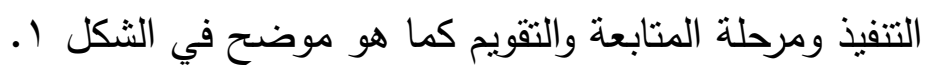
يظهر الثكل المرحلـة الأولى للتخطيط الإسـتراتيجي بأنها مرحلـة الأعداد

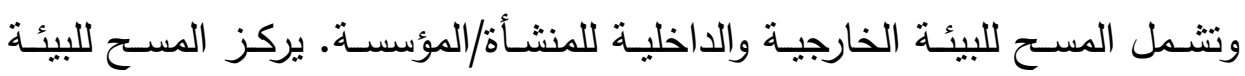
الخارجية للمنشأة/المؤسسة على متغيرين رئيسين هما الفرص المتاحة والتهديدات المباشرة والغير مباشرة (opportunities and threats) في هذه البيئة التي يمكن اعتبارها بأنها خارج تحكم الإدارة العليا للمؤسسة على المدى الزمني القصير ـ هذه هذه 
rTo

المتغيرات تخلق الظروف التي تؤثر على أنشطة المنشـأة/المؤسسـة ونشكل صفات البيئة المجتمعية (societal environment) للمنشأة و تعمل في هذا المضمار قوى لهو كبرى تؤثر بشـكل عـام على الحالـة الاقتصـادية للسـوق والحالـة التقنيـة والحالـة السياسية والقانونية وهذه القوى لا تؤثز على أنشطة المنشأة/ المؤسسة ذات المدى القصير بطريقة مباشرة ولكن غالباً نؤثر على القرارات المهمة على المدى الزمني

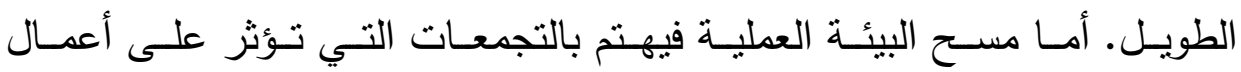
المنشـأة/المؤسسـة بشكل مباشر وتتأثز أيضـاً بأعمال المنشـأة كالجهات الحكوميـة المنظمـة والضـابطة للمهن، المؤسسـات الأخـرى العاملـة بالسـوق (المتتافسـين مـن الخارج والداخل)، العملاء، الجمعيات المهنية.

\begin{tabular}{|c|c|c|c|}
\hline مرطة & مرطلة التنفيذ & مرطة الإقرار & مرطة الأعداد \\
\hline المتابعة & (تنفيذّ الاستر اثينيات) & (رسم الاستر أنيجيات) & (المسح لنيبأة ألمنشأة/المؤسسة SWOT)) \\
\hline
\end{tabular}

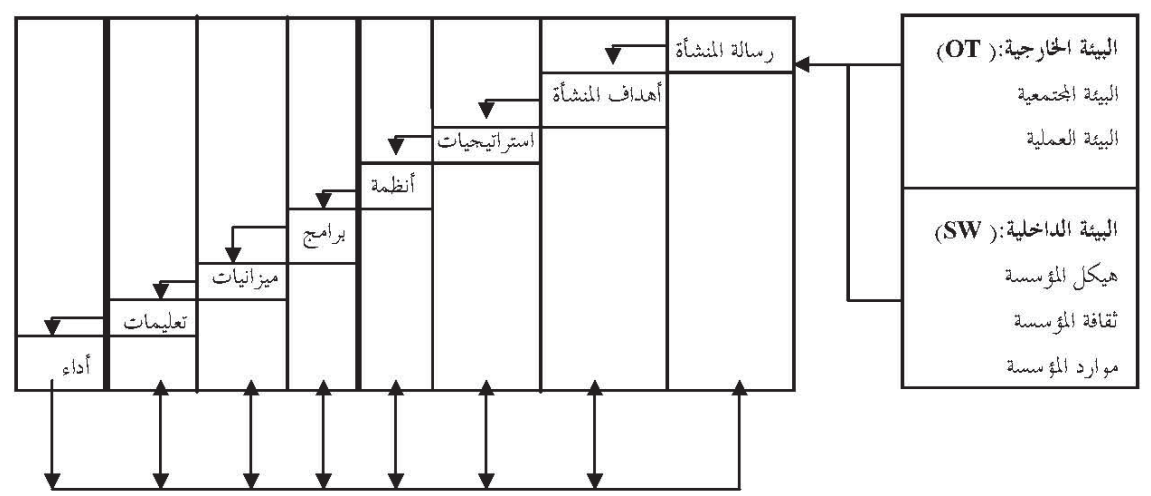

شكل 1. مراحل عملية التخطيط الإستراتيجي.

يركز المسـح للبيئة الداخلية للمنشـأة/المؤسسـة على المتغيرات ذلت العلاقة بنقاط القوة والضعف (strengths and weaknesses) داخل المؤسسة والتي لا تكون تحت سيطرة الإدارة العليا بالكل. ويشمل المسح المتغيرات للتنظيم الهيكلي بالمنشأة وتقرير هل هو مناسب أو غير مناسب لبيئة السوق (organizational structure) غير المستقرة وهل يحوز الهيكل على المرونة الكافية لتكوين مصاحبات أو الدخول 
في أحلاف مع مؤسسات أخرى تمكن المؤسسة من اختراق واكتساب أسواق جديدة ، ثقافة المؤسسـة (organizational culture) وهل هي إيجابيـة تشـع على مؤى روح الفريق الواحد، والموارد التي تعتمد عليها المنشأة في أداء عملها من بشر ومعدات ومواد وهل تتمى هذه الموارد بطرق سليمة.

المرحلـة الثانيـة لعمليـة التخطيط الاسـتراتيجي هـي مرحلـة الإقرار وتشـكيل

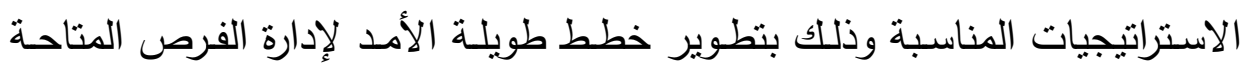

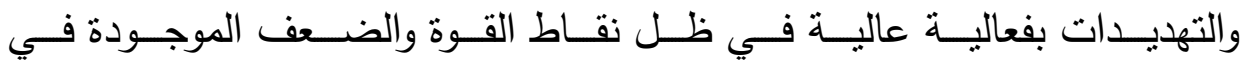
المنشـأة/المؤسسـة. هذا بعتمد بشكل أساسي على الرسـالة التي تحـاول أن تؤديها

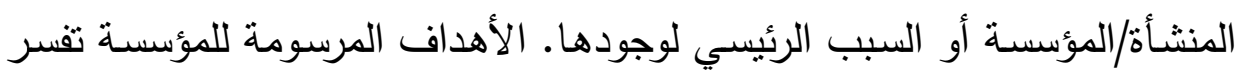

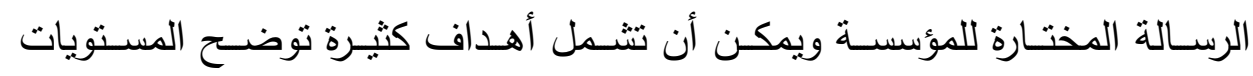
المنشودة للربح والفعالية والنمو ونسبة حيازة الأعمال الموجودة في السوق واستخدام

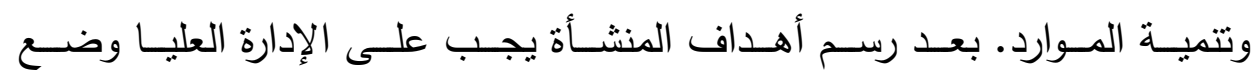

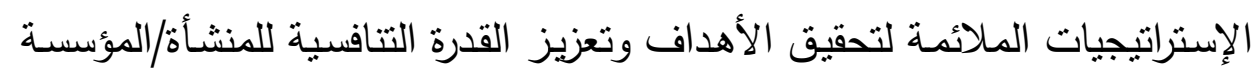
في ظل المتغيرات المتوقعة والغير متوقعة. تعقب هذه الخطوة الهامة تبني الأنظمة الملائمة للإستراتيجيات الموضوعة والتي تشكل طريق إرشادي لكيفية اتخاذ القرار

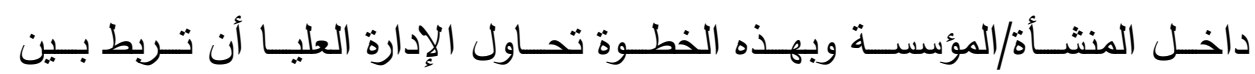
الإستراتيجيات وتتفيذها. المرحلة الثالثة لعملية التخطيط الاستراتيجي تنتخص في التهاتي التفيذ. أول خطوة في هذه المرحلة هي برمجة الإستراتيجيات في خطط والتي ربما تشمل إعادة هيكلة المنشأة/المؤسسة أو محاولة تغيير ثقافتها الحالية لتصبح أكثر برد إيجابية أو تنشيط الدعاية لخدمات المؤسسة. الخطوة الثانية في هذه المرحلة الهامة هـي وضـع ميزانيـات ماليـة لتنفيـذ الخطط والبـرامج المبنيـة على الإسـتراتيجيات

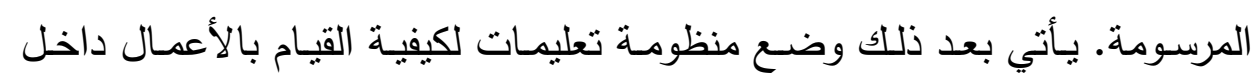
المنشـأة/المؤسسـة. المرحلـة الأخيرة هـي مرحلـة المتابعـة والتقويم للإسـتراتيجيات. 
وتقتصر هذه المرحلة على خطوة إيجاد آلية منظمة بالمنشأة/المؤسسـة لقياس مدى ترجمة الخطط الموضوعة إلى واقع و تحقيق الأهداف المرسومة. بشكل عام لا تستطيع أي مؤسسة خدمات معمارية أن تأتي إلى سوق ملىئ بالمنافسين وتحساول أن تسـوق خدمات استشـارية إذا كانـت غير متأكدة مـا هي طبيعـة ونوعيـة الخدمـة التي تحساول أن تروجها. ولذلك وأكثر من أبي شـئ آخر

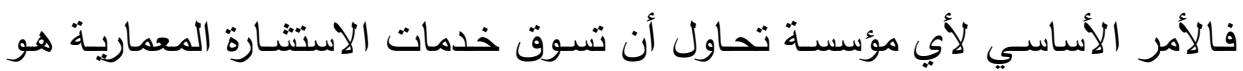
معرفـة مـا هـي الخدمـة التي تجلبهـا للسـوق والتي سـوف تميزهـا عـن المنافسـين الآخرين وبـدون الحاجـة إلى القول فـإن أي جهد لتمبيز نفسـك مـن منافسيك أو لاحتلال زاوية أو مكان معين بالسوق يلزم أن يبدأ بالتخطيط والتحليل لمعرفة نقاط

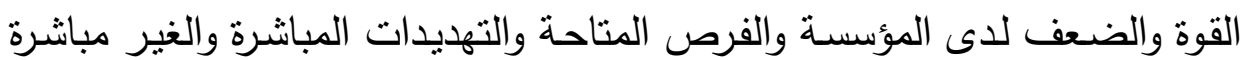
الموجودة في البيئة التتافسية من دخول منافسين جدد (خاصـة وأن معظم المشاريع المتوسطة والكبيرة في السوق المحلي في الوقت الحاضر يقوم بتتفيذها المؤسسات

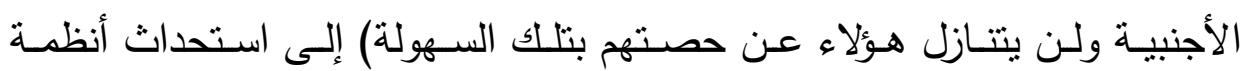
وقوانين غير مناسبة للمؤسسة إلى تطوير تقنيـة جديدة يلزم صـرف أموال وجهود

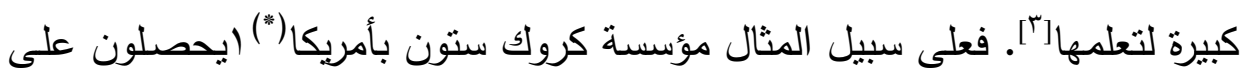

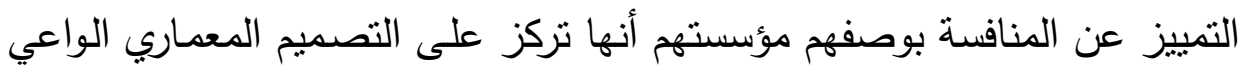

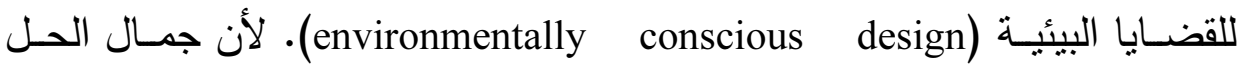
المعماريـة لا يهم في هـذا الحالـة (context) لأن معظم عمـلاء هـذا النـوع مـن الاستشارة المعمارية لا يهههم أن يروا تصميم جميل لا يراعي القضايا البيئية بقدر تصميم آخر يراعي هذه النواحي ويكون أقل جمالاً.

إذاً التحليل الذي يلزم للمؤسسة المعمارية أن تقوم به يتعلق بعناصر أساسية

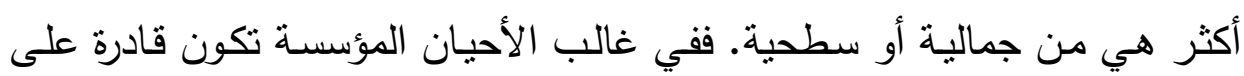


التحكم ببعض هذه العناصر إذا مـا نظر إليها بشكل جدي ولكن ليس كلها لأن هناك عناصر أخرى تكون في خارج نطاق تحكم المؤسسة. بشكل عام للكثف عن نقـاط القـوة والضــف والفـرص والتهديـدات الموجـودة فـي بيئتهـا يلـزم المؤسسـة المعماريـة أن تتظر إلى قضـايا رئيسية وتقيم سـلامتها وصـلاحيتها وتهتم بطرح تسـاؤلات أهمها تتعلق بثقافة المؤسسـة وهل هي إيجابيـة بحيث تشـجع على روح الفريق الواحد؟ كيف نرى المؤسسة نفسها من الداخل طبقاً لأراء العاملين بها؟ هل الإنتاجية وتكلفة أداء الخدمات الاستشارية مضبوطة بعناية؟ هل تعطي المؤسسة جميع أنـواع الزبائن الاهتمـام الكافي والأولوبـة قبـل وبعد الخدمـة. مـا هـي النظرة الإستراتيجية للمؤسسـة عن جودة عملية التصميم والعمليات الأخرى؟ كيف هي لري

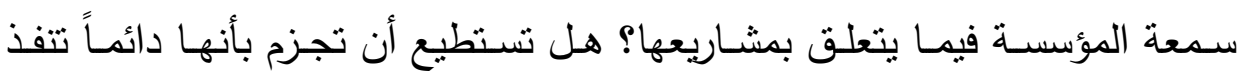

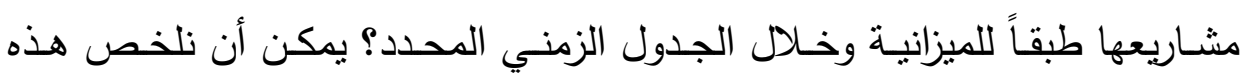
القضايا في عشرة مناطق رئيسية من المنظور الإداري بهذا النوع من المؤسسات وهي:

ا ـ الأهـداف المرسـومة والتتظيم الهيكلي (goals, structure) ז. الـنم المستخدمة (systems) r ا. عملية التصميم (design process) ع. إدارة المشاريع o (project management) وتتميتها (human resources) V. التعليهـات والضـوابط (policies) ^. التسـويق

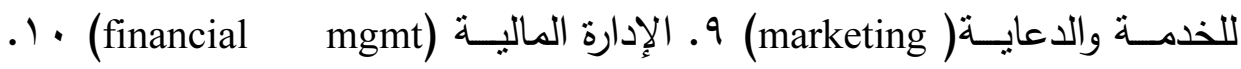
المعدات والتقنية المستخدمة (equipment, technology) [ [ـ]

يبين الثـكل (Y) والمعتمــ مـن قبـل جمعيـة المعمـاريين الأمريكيـة (AIA) لإجراء تحليل نقاط القوة والضعف لمؤسسات خدمات الاستشـارة المعمارية ويعطي إدارة هذه المؤسسات القدرة على أن تقيم مستوى العشرة مناطق المشار إليها سابقاً مع بعضها البعض وبسرعة وبكفاءة على خمس مستويات بحيث المستوى الخامس 
يساوي أقصى مستوى للمنطقة والمستوى الأول يساوي أدنى مستوى للمنطقة. ينتج من وصل العثرة نقاط الموضحة على العشرة محاور ببعضها البعض شكل بعشرة

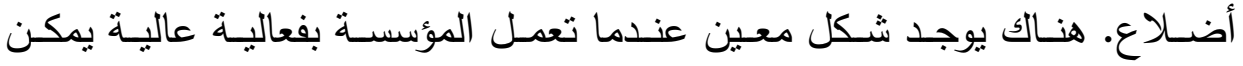
للمؤسسـة أن تعرفه بهذه الطريقة بإجراء مقارنـة بين المستويات على فترات زمنية

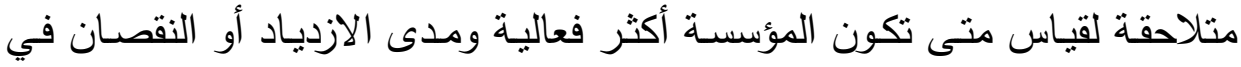

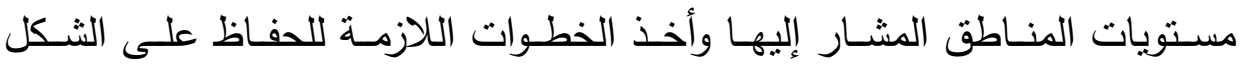
المستكثف والحفاظ على مستوياته والحيلولة من نقصانها ووضع الحلول المناسبة لتدارك المستويات المتناقصة ورفعها.

المستوى الأول

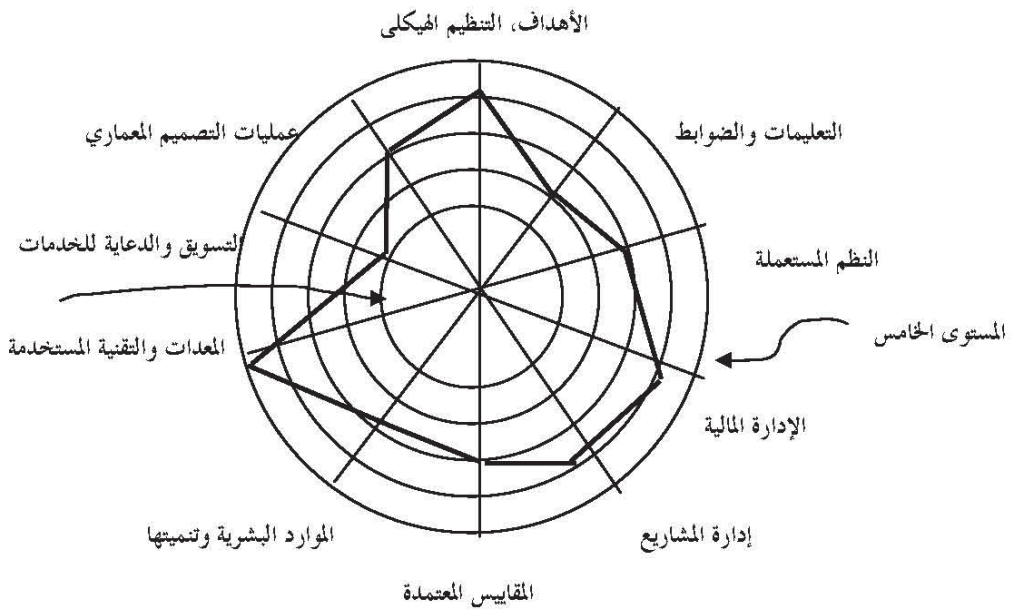

شكل ب. التحليل لنقاط القوة والضعف بمؤسسة خدمات الاستثارة المعمارية بطريقة رسم الرادار .

\section{r. جودة الخدمة والتخطيط الاستراتيجي}

في البدايـة يلزم علينـا أن نعرف مـاذا نقصد بكلمـة الجودة ومـا هي جودة الخدمة وما هي أبعادها الرئيسية. بعضهم يصفون الجودة بأنها جودة العملية التي لهي

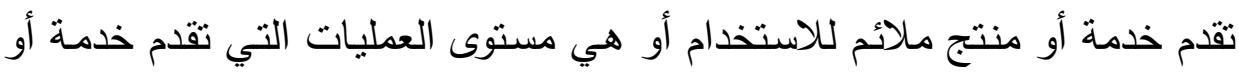


تتتج منتج وتكون خالية من العيوب أو مستوى العمليات الذي يقلل ويلغي التبذير في الجهد والتكلفة وتكون منماشية مس توقعات الزبون أو مستوى الجودة المطابق

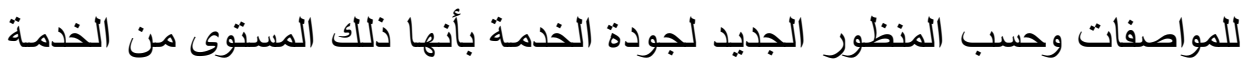

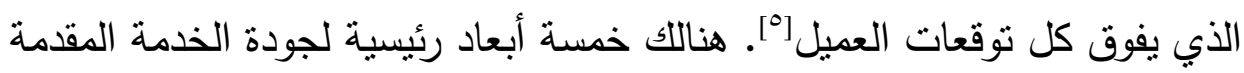
حسب أنموذج نظري لقياس جودة الخدمة المقدمة يدعى (servqual model) وهي:

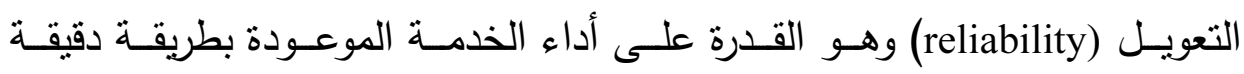
ومعتمـدة، التجـاوب (responsiveness) وهـو الرغبـة في تقديم خدمسة ذات جـودة عالية وسربعة، الضمان (assurance) وهو ائتمان وكفاءة ومصداقية الخدمة، الود ودئ (empathy)

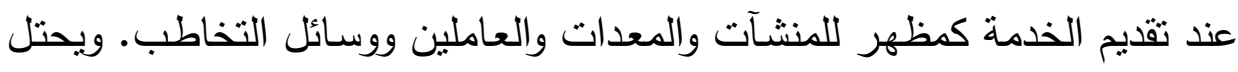
التعويـل المرتبـة الأولى بين الأبعاد الخمسـة من حيت التأثنير في جودة الخدمـة ويأتي التجاوب في المرتبة الثانية والضمان في المرتبة الثالثة والاهتمام بالعميل في

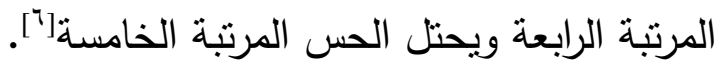

وبعتمد هذا الأنموذج في تقييم مدى رضـاء العميل/الزبون بالخدمة المقدمة على قياس الفجوة بين مستوى الجودة المدركة ومستوى الجودة المتوقعة من قبل بل فئ

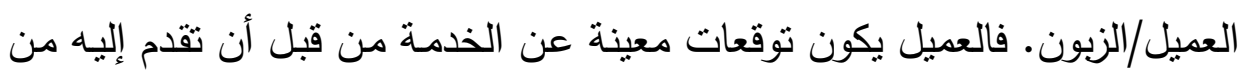

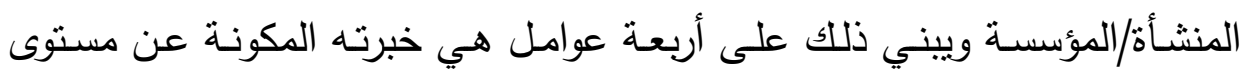
الخدمة في المؤسسة عن طريق تعامل سابق إن وجد واحتياجاته الخاصة بالخدمة

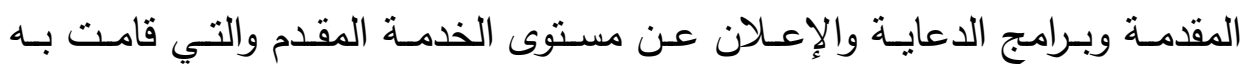
المؤسسـة ورأي الزبائن الآخرين إن وجدوا في مستوى الخدمـة المقدم. وبعد تقديم الخدمة يكون لدى العميل /الزبون إحساس وإدراك بمستوى الخدمة التي قدمت إليه

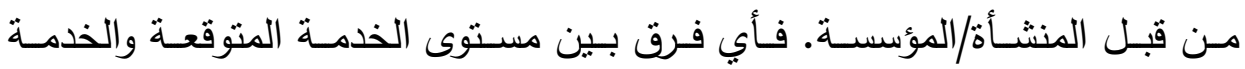
المحسوسة يؤثز في مستوى الجودة المدركة من قبل العميل. وتستخدم هذه الدراسـة هذه الطريقة لقياس مدى رضاء العملاء عن جودة الخدمات المقدمة لهم. 


\section{ع ـ الدراسة}

تم الأخذذ بالاعتبـار فـي هـذه الدراسـة المؤسسـات والمكاتـب الاستشـاربة المعماريـة المصـرح لها بالعمل في مكة المكرمـة وجدة وهم حوالي بآ 1 مؤسسـة

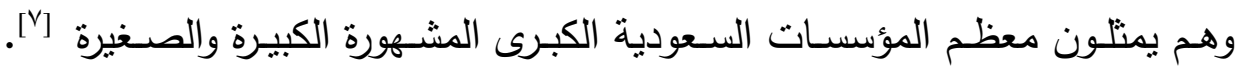
قامت الدراسة بتقصي مستوى تطبيق ثلاثة مبادئ رئيسية في هذه المؤسسات وهي التخطيط الاسـتراتيجي وإجـراء تحليـل (SWOT)، إرضـاء العميـل/الزبـون وتقديم خدمات تفوق توقعاته، خلق بيئة عمل وثقافة مؤسسـة إيجابية تشجع روح الفريق الواحد والولاء والانتماء بين العاملين. صمدت للاراسـة ثلاثة أنواع من الأستبانة. النوع الأول ركز على طبقة العـاملين (كمعـاريين، ورسـامون) بالمؤسسات والنوع الثاني خصص لطبقة الإدارة العليا بالمؤسسات العاملة. ووزع عدد (rT I ) استبانة من كل النوع الأول والثاني على جميع هذه المؤسسات بواسطة البريد الرسمي. أمـا النوع الثالث من الأستبانة فوزع بطريقة عشوائية مناولة على عمـلاء المؤسسـات المعمارية الذين حضروا للحصول على ترخيص للبناء وذللك لقياس مدى رضائهم بالخدمـة المقدمـة من المؤسسـات المعماريـة الاستشـارية المرخص لها بالعمل. في الاســتبانة الأولــى اسـتخدمنا طريقــة (Maloney) فـي تقيــيم ثقافــة المؤسســة والذي يعتمد التقييم فيها على حساب الفرق في الإدراك (organizational culture) بين العـاملين وبين الإدارة فيمـا يتعلق بسـنة قضـايا أساسية للمؤسسـة وهي نمط القيادة المتبع، معايير النجاح في المؤسسـة، مدى التزام القيادة، الأسلوب الإداري المتبـع، مسـتوى التـرابط الموجـود في المؤسسـة (روح الفربـق الواحد). فكلمـا كـان الفرق كبير بين إدراك طبقة العاملين وبين إدراك الطبقة الإدارية لمجريات الأمور كانت الثقافة ضعيفة وغير مجدية للمؤسسة وكلما تقلص هذا الفرق كانت التقافة مجدية ومناسبة للمؤسسة [^]. 


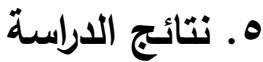

تم تجميع إجابـات كاملـة لعدد (ع 0) مؤسسـة على أسئلة الأستبانة الأولى

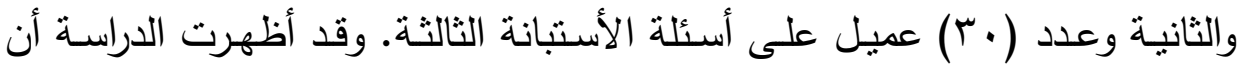
نسبة كبيرة ( حوالي . ^ ٪) من المؤسسات والتي قامت بإجابة أسئلة الأستبانة من

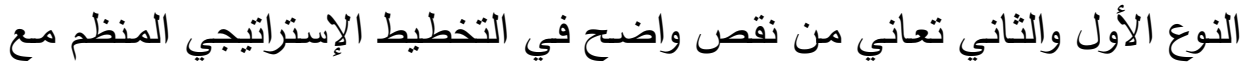
العلم بأن حوالي 90 ٪ من المؤسسات أوضحت بأن لديها رسالة وأهداف تقليديـة كالربح وخدمة العميل ولكنها لا تقوم بتركيز عملية التخطيط الإستراتيجي الموضـح

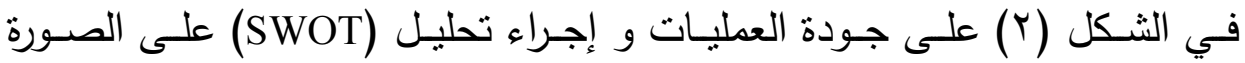
المطلوبة وحتى لو أجري فأنه بصورة متقطعة على فترات طويلة وليست منتظمة

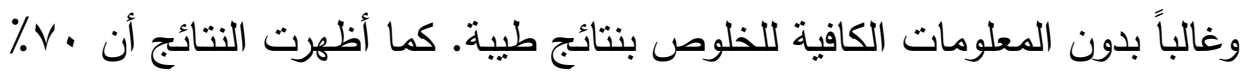
مـن هذه المؤسسـات تعـاني ثقافـات ضـعيفة وتوجد فجـوة كبيـرة بـين إدراك طبقـة العاملين وبين إدراك طبقة المسئولين عن هذه المؤسسات عن الظروف والأحوال

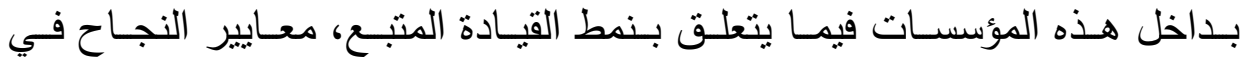

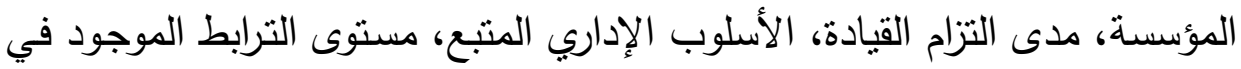

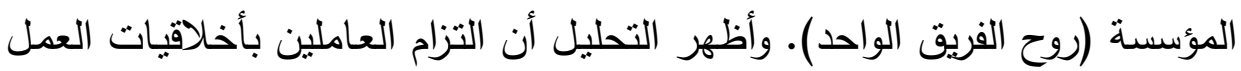
السليم مع غياب بيئة العمل المناسبة لديناميكية السوق.

لتقييم مدى رضـاء العميل استخدمت الطريقة المتبعة في الأنموذج المطور لتقييم جودة الخدمـة (SERVEQUAL Model) والمبني على قياس مدى إدراك العمبل لجودة الخدمـة المقدمـة. هذا وقد ظهر من حصيلة الاستبيانات التي قام T/ I عميل بتعبئتها أن مستوى الرضاء بالخدمة المقدمة بشكل عام متدن جداً بين

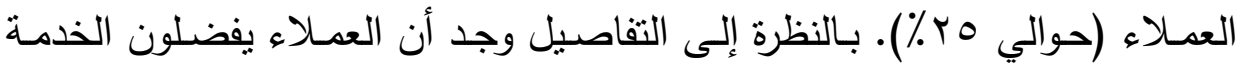

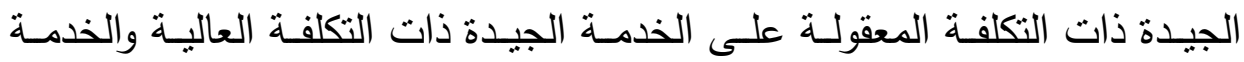
المتدنية ذات التكلفة المنخفضة. أظهرث أجوبة العملاء بأن الخدمة المقدمة تعاني دأ دات في المقام الأول من انخفاض مستوى التجاوب والرغبة لدى المؤسسات في تقديم

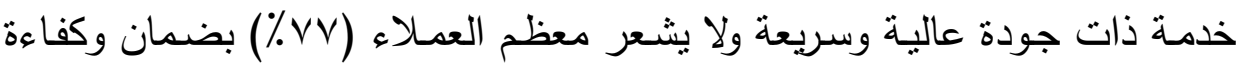


ومصداقية الخدمة إلا إذا تعاقدوا مع المؤسسة عن طريق معرفة مشتركة أو توصية من صديق أو عزيز لاى صاحب المؤسسة.

أوضـح نسبة كبيـرة مـن العمـلاء المشـتركين في الدراسـة (ب7\%) أن هنـالك

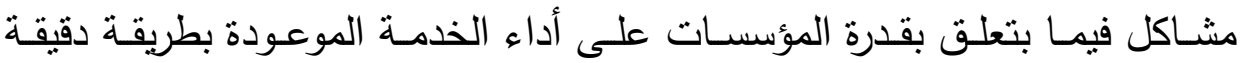
ومعتمدة ومشاكل تتعلق بكفاءة المؤسسات للقيام بالدراسات الكافية للمشاريع نظراً

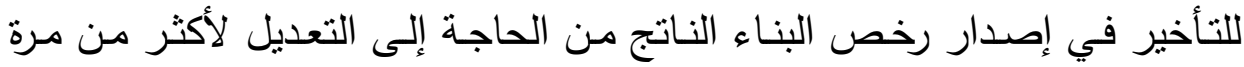

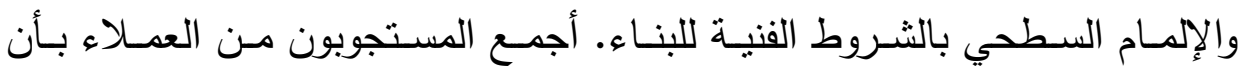
الاهتمام بالعميل ومظهر الخدمة ليس كما يجب وأن مكاتب المؤسسات تعاني من

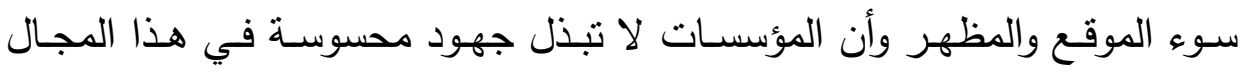
لتحسين وضـعهم حيـث أثـار (10\%) مـن العمـلاء بـأن مظهر أمـاكن الاجتمـاع والانتظار بمكاتب المؤسسات كان غير لائق بمستوى العميل.

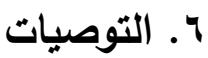

توصي نتائج الدراسة بالتالي:

- علـى المؤسسـات المعماربـة المحليـة أن تقـوم باسـتيعاب وفهم عمليـة التخطيط الاستراتيجي وكيفية تطبيقها في مؤسساته والسعي الجاد والحثيث لتطبيق أسسها ومبادئها بصورة منتظمة.

- نظراً للوضع الحرج لهذه المؤسسات فعليها الإسراع في جمع المعلومات الصــحيحة والواقعيـة للقيـام بتطبيـت تحليـل (SWOT) ومســح بيأـتهم الداخليـة

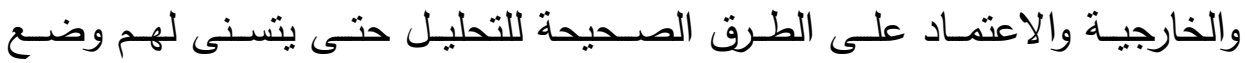
الإستراتيجيات المناسبة لهم.

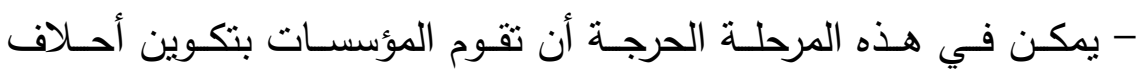
وتكتلات لزيادة التعاون بينهم تعتمد على نقاط القوة لكل مؤسسة بطربقة تضمن أن تتفذ الأعمال بنكلفة منافسة وبجودة عالية تساعد على منع اختراق السوق المحلي. 
- التركيز على تطبيـق مبـادئ الجـودة الثـاملة والتتي بـرهن على جدوى استخدامها في رفع الأداء ثورة الجودة العالمية الحالية والتي تتادي بتطبيق الجودة

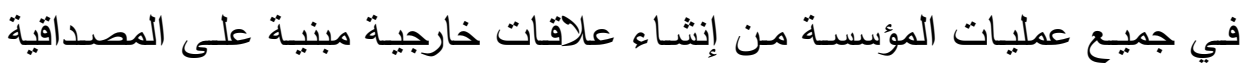
والنزاهة إلى بناء ثقافة داخلية نتجع روح الفريق الواحد بين العاملين - رفـع كفـاءة وفاعليـة العـاملين لـدى المؤسسـات بعدة طـرق منهـا بـرامج

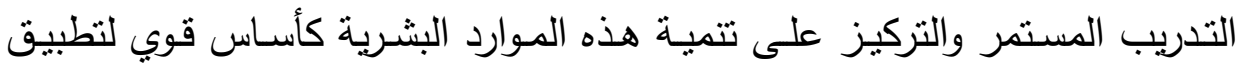
مبادئ الجودة الثاملة.

- رفـع درجـة الاهتمـام بالعميـل والتركيز على إرضــاءه قبـل مرحلـة تقديم

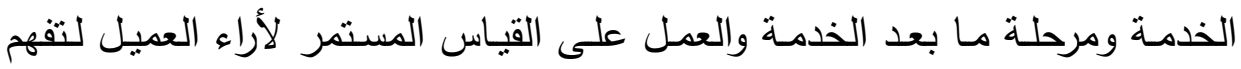
احتياجاتهم ورغباتهم المتغيرة بشكل مستمر ومدى رضائهم عن الخدمة.

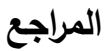

[1] العشيش، صالح (1997) " إدارة تنفيذ المشروعات الهندسية"، مكتبة العبيكان، الرياض.

Hunger, D. and Wheelen, T. (1999) "Strategic Management", Addison-Wesley Publishing [Y] Company, Inc. Jim, M. (1998) "Management for the Small Design Firm: Handling Your Practice, [ץ]
Personnel, Finances, and Projects", Whitney Library of Design, New York.

Stasiowski, F. and Burstein, D. (2001) "Total Quality Project management for The Design [ [ ] Firm" John Wiley \& Sons, Inc.

Garvin, D. (1998) "Managing Quality: The Strategic and Competitive Edge", The Free [०] Press, New York.

Zeithamal, V. et al.,(2000) "Delivering Quality Service: Balancing Customer Perceptions and Expectations", The Free Press, New York.

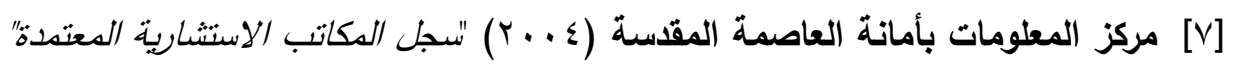

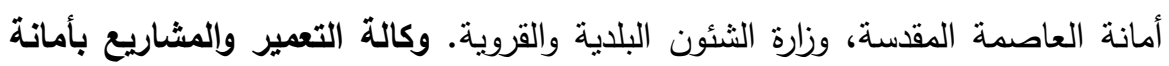

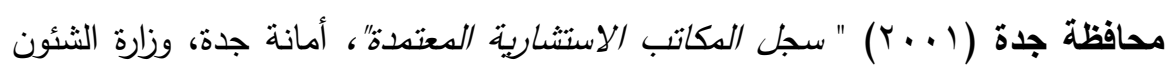
البلدية والقروية.

Maloney, W. F., and Federle, M. (1993) "Practical Models for Organizational Assessment", ASCE Journal of Management in Engineering, 9(1): 64-81. 


\title{
Architectural Firms in Saudi Arabia: Strategic Planning \& Effectiveness of Professional Practice
}

\author{
Adnan A. Adas \\ Architecture Dept., Faculty of Environmental Designs, King Abdulaziz \\ University, Jeddah, Saudi Arabia
}

(Received: 09/05/2005, Accepted: 17/11/2005)

\begin{abstract}
The joining process by Saudi Arabia as full member to the World Trade Organization (WTO) is near completion. This will open the local markets to fierce competition from sophisticated foreign architectural design firms seeking growth into new markets. In turn this will have a huge impact on firms offering architectural design consultation services and operating in the local markets. In this context and beside other issues that have to be dealt with, local firms must adopt principles of strategic planning in order to enhance their capabilities to withstand in the face of any external competition.
\end{abstract}

In the first part, the paper discusses a model for the process of strategic planning. In the second part, the paper discusses the strategic planning process in general and how it can be applied from the perspective of architectural design firm to enhance its effectiveness. The paper discusses the results of a study that was carried out in to provide a look into the status of firms offering architectural design consultation services. The study evaluated the strength of organizational culture in these firms using the Maloney method. It judged the level of strategic planning and level of using SWOT analysis by upper management and measured level of service quality using a valid model named (SERVQUAL). Finally the paper concludes by discussion of a number of alternatives that could be used by local architectural firms to bolster their position and increase their chance for effective participation while operating under the WTO rules. 